\title{
Fatal Complications and Early Death after Surgical Treatment of Lung Cancer in 2000 and 2010. A Population Based Study
}

\author{
Hans Rostad \\ Cancer Registry of Norway, Norway \\ Email: hans.rostad@kreftregisteret.no
}

Received November 9, 2012; revised December 11, 2012; accepted December 20, 2012

\begin{abstract}
In the year 2000 lung cancer was operated in 349 patients in Norway, in 2010 the number was 461. In the first period fatal surgical hemorrhage occurred in eight patients, in four of them peroperatively. Postoperative hemorrhage occurred in four patients in the year 2000 and in two in 2010. Ten patients died intra- or postoperatively in the two periods which is a mortality rate within 30 days after surgery of $4.3 \%$ in the first and $1.1 \%$ in the second period. Pneumonectomy was performed in 34 patients in 2000 and eight in 2010, respectively. Altogether 19 patients died within six months after surgery without having experienced surgical complications. Pneumonectomy should not be performed in elderly and debilitated persons.
\end{abstract}

Keywords: Lung Cancer Complications

\section{Introduction}

The Cancer Registry of Norway is a nation-wide institution. It is regulated by law that all clinical and pathology departments submit standardized reports on cancer patients to the Registry. Furthermore, the Registry has a law-regulated authority to collect supplemental information on the diagnosis, treatment and outcome of all cancer patients from hospitals in charge. Finally, the Registry receives death certificates from the Central bureau of Statistics regarding all patients having cancer as the cause of death. The Surgical Registry is one of the most detailed in the world. Data from the Registry include important contribution to the new TNM classification for lung cancer, determined by the International Association for the Study of Lung Cancer (IASLC).

In Norway lung cancer is the second most frequent cancer disease both in men and women but it is the cancer with the highest mortality.

During the last 10 years lung cancer has annually been diagnosed in 2000 - 2500 persons in Norway, and of those 300 - 500 are referred to surgical treatment which gives a resection rate of $15 \%$ - 20\% (including small cell lung cancer). Since surgery is known to be the main treatment modality to cure lung cancer our research over the last decade has been focused upon varies aspects of the surgical treatment of lung cancer. In 2002 we published the results for a survey of more than 1000 patients in the nation who were treated conservatively, to find out if some of these patients could have been operable and thus treated surgically [1]. After the exclusion of 166 patients for various reasons, almost 400 were found inoperable due to advanced disease. Of the remaining patients, 270 were classified as being operable and 127 possibly operable. We concluded that the policy in Norway concerning evaluation and treatment of lung cancer patients was inadequate and requested lung physicians to be more aggressive for this group of patients. Because of favorable short and long time results we have recommended this aggressive approach to patients with lung cancer, even with small cell types [2-4]. We have communicated this opinion in numerous international and Norwegian forums and journals. After all these years with research and publishing of several articles mainly on surgical treatment we were interested to see if there had been any improvement in the handling of patients with lung cancer.

The aim of the present study was therefore to compare the early results of surgical resection of lung cancer in the years 2000 and 2010.

\section{Material and Methods}

Data was retrieved from the retrospective database of surgical lung cancer patients within the Cancer Registry of Norway, containing detailed information on virtual all resections in the whole nation. In year 2000 lung cancer was diagnosed in 2085 patients, 349 were operated, in 
2010 the numbers were 2829 and 461, respectively. The resection rate has been increasing from $10 \%-12 \%$ to almost 20\%. In 2000 lung cancer surgery was performed at 25 different hospitals, this was reduced to 9 in 2010, most of them University hospitals The surgical procedures and death within 30 and 60 days after surgery were evaluated in patients 70 years or more at the operation.

\section{Results}

In 2000 fatal hemorrhage occurred in eight patients, in four of them peroperatively (Table 1). In a 70 years old man there was serious bleeding from a lung vein and perforated right ventricle. A 76 years old man should have removed peripheral tumor with a diameter of $2 \mathrm{~cm}$ thoracoscopically. By accident a large central tear in the pulmonary artery occurred and could not be repaired despite thoracotomy, and the patient was lost. In two other patients, 53 and 79 years old massive bleeding from the pulmonary artery could not be controlled. There was postoperative hemorrhage in four patients in 2000 and two in 2010. Four patients with postoperative hemorrhage were reoperated, all died. Postoperative hemorrhage was found at autopsy after two months and three weeks postoperatively. Four of these surgical hemorrhages occurred in University hospitals and 6 in so called Central hospitals.

Broncho-pleural fistula occurred postoperatively in three patients in the year 2000 and one in 2010 (Table 2).

Postoperative mortality of the patients operated in the year 2000 after 30 and 60 days was $4.3 \%$ and 6\%, respectively. Similar results in 2010 were $1.1 \%$ and $1.1 \%$, (Table 3).

Table 1. Characteristics of hemorrhage complications.

\begin{tabular}{ccc}
\hline & Year 2000 & Year 2010 \\
\hline Peroperatively hemorrhage & 4 & 0 \\
Postoperatively hemorrhage & 4 & 0 \\
Right lung & 2 & 1 \\
Left lung & 3 & 1 \\
Age (years) & $48-79$ & $63-69$ \\
Diseased & 8 & 2 \\
\hline
\end{tabular}

Table 2. Number of broncho-pleural fistulas.

\begin{tabular}{rcc}
\hline & Year 2000 & Year 2010 \\
\hline Right lung & 2 & 0 \\
Left lung & 1 & 1 \\
Diseased & 3 & 1 \\
\hline
\end{tabular}

In the year 2000 pneumonectomy was performed in 34 patients while the corresponding number in 2010 was eight (Table 4). In the first period 15 patients died 60 days after the procedure, and one in the last. The number of lobectomies was almost twice as high in 2010 compared to 2000.

Altogether 19 operated patients died within six months after surgery without experiencing surgical complications (Table 5). Pneumonia, myocardial infarction and respiratory insufficiency were dominating causes. A few of them suffered some degree of chronic obstructive lung disease because history of smoking. One of those who died from myocardial infarction had undergone coronary artery bypass surgery a few years earlier. Three died from cerebral stroke three days to three months postoperatively.

Table 3. Postoperative mortality.

\begin{tabular}{ccc}
\hline & Year 2000 & Year 2010 \\
\hline N (\%) & $\mathrm{N}(\%)$ \\
Less than 30 days & $15(4.3)$ & $6(1.1)$ \\
Less than 60 days & $21(6.0)$ & $6(1.1)$ \\
\hline
\end{tabular}

Table 4. Surgical procedures and postoperative death in patients more than 70 years.

\begin{tabular}{ccccccc}
\hline & \multicolumn{3}{c}{ Year 2000 } & \multicolumn{3}{c}{ Year 2010 } \\
\hline & $\begin{array}{c}\mathrm{N} \\
\text { deaths }\end{array}$ & $\begin{array}{c}<30 \\
\text { days }\end{array}$ & $\begin{array}{c}<60 \\
\text { days }\end{array}$ & $\begin{array}{c}\mathrm{N} \\
\text { deaths }\end{array}$ & $\begin{array}{c}<30 \\
\text { days }\end{array}$ & $\begin{array}{c}<0 \\
\text { days }\end{array}$ \\
Left lung & 22 & 9 & 11 & 4 & 0 & 0 \\
Right lung & 12 & 2 & 4 & 4 & 1 & 1 \\
Lobectomy & 77 & 2 & 3 & 130 & 2 & 2 \\
Bilobectomy & 12 & 3 & 3 & 8 & 0 & 0 \\
Sublobar & 12 & 0 & 0 & 13 & 0 & 0 \\
resection & & & & & &
\end{tabular}

Table 5. Early death ( $<6$ months) after lung cancer surgery without surgical complications.

\begin{tabular}{|c|c|c|c|}
\hline Cause of death & $\mathrm{N}$ & $\begin{array}{l}\text { Interval from } \\
\text { surgery to death }\end{array}$ & $\begin{array}{c}\text { Range of } \\
\text { patients age }\end{array}$ \\
\hline Pneumonia & 5 & 2 weeks - 5 months & $61-82$ \\
\hline $\begin{array}{l}\text { Myocardial } \\
\text { infarction }\end{array}$ & 4 & 2 days - 2 months & $67-76$ \\
\hline $\begin{array}{l}\text { Respiratory } \\
\text { insufficiency }\end{array}$ & 3 & 4 days - 3 months & $57-80$ \\
\hline Cerebral stroke & 3 & 3 days - 3 months & $45-72$ \\
\hline $\begin{array}{c}\text { Lung cancer } \\
\text { with metastases }\end{array}$ & 2 & 53 days -3 months & $65-80$ \\
\hline $\begin{array}{l}\text { Pulmonary } \\
\text { embolism }\end{array}$ & 1 & 6 months & 73 \\
\hline $\begin{array}{c}\text { After } \\
\text { laparotomy }\end{array}$ & 1 & 1 month & 76 \\
\hline
\end{tabular}




\section{Discussion}

The results of this report demonstrate that lung cancer surgery is associated with a relatively high frequency of complications and death particularly in the early part of this century [5]. However, the difficult question may be posed: What risk should be accepted for surgery to be performed in order to cure a disease with near $100 \%$ mortality if left unresected? One potential cause of the high frequency of complications and fatality is the fact that thoracic surgery was performed in 25 different hospitals in the first period. A considerable centralization of lung cancer surgery in the country is considered to be a major reason for the better short time results [6]. Another important factor is that risky procedures like pneumonectomy was performed even in aged patients $(>70$ years) in the year 2000 [7]. When these procedures were reduced considerably in 2010 the mortality fell to acceptable levels. In our many published reports we always warned against extensive procedures in old and debilitated persons [5]. Another possible factor for the improved postoperative results in 2012 may be that tobacco smoking has been reduced considerably in Norway during the first years of this century [8].

In conclusion, there was considerable more number of surgical hemorrhages in the year 2000 compared to 2010. An important reason may be great number of pneumonectomies in the first period. Despite the occurrence of complications even in University hospitals it is reason to believe that the centralizing of lung cancer surgery the last years has been favorable for this group of patients.

\section{REFERENCES}

[1] H. Rostad, A. Naalsund, J. Norstein, et al., "Is the Treat- ment of Lung Cancer in Norway Adequate?” Tidsskrift for Den Norske Legeforening, Vol. 122, No. 23, 2002, pp. 2258-2262.

[2] H. Rostad, A. Naalsund, R. Jakobsen, et al., "Small Cell Lung Cancer in Norway. Should More Patients Have Been Offered Surgical Therapy?” European Journal Cardio-Thoracic Surgery, Vol. 26, No. 4, 2004, pp. 782-786. doi:10.1016/j.ejcts.2004.06.011

[3] T. E. Strand, H. Rostad, B. Møller, et al., "Survival after Resection for Primary Lung Cancer: A Population Based Study of 3211 Resected Patients,” Thorax, Vol. 61, No. 8, 2006, pp. 710-715. doi:10.1136/thx.2005.056481

[4] H. Rostad, H. Strøm, H. Scott, et al., "Small Cell Lung Carcinoma. Better than Its Reputation? A Population Based Study," Journal of Interdisciplinary Histopathology, Vol. 1, No. 1, 2012, pp. 1-4.

[5] H. Rostad, T. E. Strand, A. Naalsund, et al., "Lung Cancer Surgery: The First 60 Days. A Population Based Study," European Journal Cardio-Thoracic Surgery, Vol. 29, No. 5, 2006, pp. 824-828. doi:10.1016/j.ejcts.2006.01.055

[6] T. E. Strand, K. Bartnes and H. Rostad, "National Trends in Lung Cancer Surgery,” European Journal CardioThoracic Surgery, Vol. 42, No. 2, 2012, pp. 1-4.

[7] H. Rostad, A. Naalsund, T. E. Strand, et al., "Results of Pulmonary Resection for Lung Cancer in Norway, Patients Older than 70 Years," European Journal CardioThoracic Surgery, Vol. 27, No. 2, 2005, pp. 325-328. doi:10.1016/j.ejcts.2004.11.006

[8] T. E. Strand, C. Malayeri, P. Eskonsipo, et al., "Adolescent Smoking and Trends in Lung Cancer Incidence among Adults in Norway 1954-1998," Cancer Causes \& Control, Vol. 15, No. 1, 2004, pp. 27-33. doi:10.1023/B:CACO.0000016575.31651.b0 